\title{
Flow Chemiluminescence Determination of Antimony(III,V) Using a Rhodamine B-Cetyltrimethylammonium Chloride Reversed Micelle System Following Liquid-Liquid Extraction
}

\author{
Tomoyuki Yamamoto, * Yusuke Tsunemine, ${ }^{*}$ Fumio Hayakawa, $*$ Tamer H. A. Hasanin, ${ }^{* *}$ \\ Yasuaki OKaмото, ${ }^{*}$ Shoji IshizaKa, ${ }^{*}$ and Terufumi FujIWARA $* \dagger$ \\ *Department of Chemistry, Graduate School of Science, Hiroshima University, Kagamiyama, \\ Higashi-Hiroshima 739-8526, Japan \\ **Department of Chemistry, Faculty of Science, Minia University, El-Minia, 61519, Egypt
}

\begin{abstract}
A flow chemiluminescence (CL) method combined with a liquid-liquid extraction technique is proposed for the indirect determination of antimony in aqueous samples using rhodamine B (RB). In the liquid-liquid extraction process, the antimony(V) chloro-complex anion, $\left[\mathrm{SbCl}_{6}\right]^{-}$, was extracted from an aqueous acidic solution into toluene via ion-pair formation with the protonated $\mathrm{RBH}^{+}$ion. Upon mixing the extract with a reversed micellar reagent solution of cetyltrimethylammonium chloride (CTAC) in 1-hexanol-cyclohexane/water $\left(0.60 \mathrm{~mol} \mathrm{dm}^{-3} \mathrm{H}_{2} \mathrm{SO}_{4}\right)$ containing cerium(IV), uptake of the ion-pair by CTAC reversed micelles occurred easily, followed by an oxidation reaction of RB with $\mathrm{Ce}(\mathrm{IV})$ in the CL process. The CL signal produced was then measured. Using a flow injection system, the detection limits (DL) of $0.25 \mu \mathrm{mol} \mathrm{dm}{ }^{-3} \mathrm{Sb}(\mathrm{III})$ and $0.20 \mu \mathrm{mol} \mathrm{dm}{ }^{-3} \mathrm{Sb}(\mathrm{V})$, and linear calibration graphs with dynamic ranges from the respective DLs to $16 \mu \mathrm{mol} \mathrm{dm}{ }^{-3}$ for $\mathrm{Sb}(\mathrm{III})$ and $\mathrm{Sb}(\mathrm{V})$ were obtained under optimized experimental conditions. The proposed method was successfully applied to a mixture of $\mathrm{Sb}(\mathrm{III})$ and $\mathrm{Sb}(\mathrm{V})$, where total antimony, $\mathrm{Sb}(\mathrm{III})+\mathrm{Sb}(\mathrm{V})$, was measured using ceric sulfate as an oxidant to oxidize $\mathrm{Sb}(\mathrm{III})$ to $\mathrm{Sb}(\mathrm{V})$ prior to extraction, $\mathrm{Sb}(\mathrm{V})$ was determined directly without the use of an oxidant, and $\mathrm{Sb}(\mathrm{III})$ was calculated by difference.
\end{abstract}

(Received August 31, 2012; Accepted October 5, 2012; Published January 10, 2013)

\section{Introduction}

Antimony and its compounds are widely used in a variety of products, and industrial and commercial materials including various alloys, ceramics, glasses, plastics and synthetic fabrics. It is known that antimony is one of the toxic metals; the toxicity of antimony depends on the oxidation state. In order to determine low concentrations of antimony, many methods based on different principles have been proposed. ${ }^{1-6}$ However, most of the reported methods lack either selectivity or sensitivity.

The unique applications of chemiluminescence (CL) in analytical chemistry have made the most of the advantages presented by the method's high sensitivity, wide dynamic range, and simplicity of instrumentation. Application of CL has been extensively reported in fields of drug analysis, organic contamination determination, inorganic ion assay, peroxide and amino acid determination, etc. ${ }^{7,8}$ Especially, analytical methods based on CL reaction of only a few CL reagents such as luminol are famous for their inherent simplicity, speed and high sensitivity. ${ }^{9}$ However, many inorganic anions like the antimony(V) chloro-complex anion, $\left[\mathrm{SbCl}_{6}\right]^{-}$, do not cause luminol CL and thus applications of flow injection CL methods for anion determination have been limited. ${ }^{10}$ In order to extend the use of the CL method for practical analysis, on the other

† To whom correspondence should be addressed.

E-mail: tfuji@sci.hiroshima-u.ac.jp hand, rhodamine compounds as a series of xanthene dyes are attracting increasing attention as highly sensitive and selective CL reagents. As is well known, rhodamine $B(R B)$ has been applied in analytical chemistry, ${ }^{11,12}$ mostly in spectrophotometry ${ }^{13}$ and fluorescence analysis. ${ }^{14}$ It has been reported recently that $\mathrm{CL}$ emission could be generated by the oxidation of RB. The behavior of a new CL system, cerium(IV) with RB in an acidic medium, was investigated. ${ }^{15}$

The utility of micelles and microemulsions and their analytical applications are numerous. ${ }^{16-18}$ In the reversed micellar solution, the surfactant molecules encompass tiny water droplets, surrounded by surfactant polar heads, and are converted into homogeneously distributed micelles in the organic bulk. Acting as microreactors, ${ }^{17}$ the reverse micelles possess unique properties. When reversed micelles are incorporated into the CL detection system, several advantages, including sensitivity and improved selectivity, are achieved. ${ }^{18-27,29}$ It is believed that the reversed micellar-mediated CL (RMM-CL) reactions occur at water-surfactant interfaces of the reverse micelles. ${ }^{18,19,23} \mathrm{We}$ have pointed out that the uptake of CL-active species or CL reagents by reversed micelles into their water pools is significant in the RMM-CL process. ${ }^{20,21,24,25,27-29}$ In our previous work, the RMM-CL behavior of RB was investigated using the acidic water pool containing the $\mathrm{Ce}(\mathrm{IV})$ oxidant in the reversed micellar medium of cetyltrimethylammonium chloride (CTAC) in 1-hexanol-cyclohexane. ${ }^{29}$ When the reversed micellar solution of $\mathrm{Ce}(\mathrm{IV})$ was mixed with the $\mathrm{RB}$ solution in 1-hexanol-cyclohexane using a flow injection (FI) system, 
stronger CL emission from RB was observed compared with that in the usual aqueous solution.

To improve selectivity of the CL methods, various separation techniques such as chromatography, gas generation, and membrane separation are usually incorporated into the flow CL detection systems..$^{30,31}$ Liquid-liquid extraction is one of the most effective separation methods. We have developed new hybrid analytical methods based on the combination of extraction procedures with the RMM-CL detection system. ${ }^{19,22,25,26}$ For the liquid-liquid extraction of $\mathrm{Sb}(\mathrm{V})$, an ion-pair formation between the protonated rhodamine $\mathrm{B}$, $\mathrm{RBH}^{+}$, and the negatively charged $\mathrm{Sb}(\mathrm{V})$ chloro-complex, $\left[\mathrm{SbCl}_{6}\right]^{-}$, was described earlier by Ramette and Sandel. ${ }^{32}$ The technique has come to be regarded as an efficient analytical method for $\mathrm{Sb}(\mathrm{V})$ detection. The same principles are extended to the present work, where the above RMM-CL detection using a RB-Ce(IV) reaction is applied to the indirect determination of $\mathrm{Sb}(\mathrm{V})$ extracted from aqueous sample solutions. To the best of our knowledge, no investigation of the utility of RB, not only as an extracting reagent but also as a CL reagent, has been reported so far for a hybrid method based on the combination of liquid-liquid extraction with a CL detection system. In this work, the feasibility of using RB as both reagents was examined for the proposed method, where CL active conditions compatible with the extraction should be selected. Furthermore, validation of the present method was confirmed by applying it to a speciation analysis of $\mathrm{Sb}(\mathrm{III}, \mathrm{V})$, where a reaction process using the $\mathrm{Ce}(\mathrm{IV})$ oxidant was added for oxidizing $\mathrm{Sb}(\mathrm{III})$ to $\mathrm{Sb}(\mathrm{V})$ prior to extraction.

\section{Experimental}

\section{Chemicals and reagents}

Rhodamine B, ceric sulfate tetrahydrate, hydroxylamine hydrochloride and hydrochloric acid were purchased from Wako Pure Chemical Industries Ltd. (Osaka, Japan). Cyclohexane, 1-hexanol, toluene and metal standard solutions used for interference studies were obtained from Kanto Chemical Co., Inc. (Tokyo, Japan). Potassium pyroantimonate and sulfuric acid were obtained from Katayama Chemical Industries (Osaka, Japan). The surfactant CTAC was obtained from Tokyo Chemical Industry Co. Ltd. (Tokyo, Japan). All other reagents used were of analytical reagent grade. All chemicals were used without purification. All aqueous solutions were prepared with deionized water purified with a Millipore Milli-Q system (Merck Millipore, Milli-Q integral 3). A $5.0 \mathrm{mmol} \mathrm{dm}^{-3} \mathrm{RB}$ stock solution was prepared in water. The oxidant solution of $0.10 \mathrm{~mol} \mathrm{dm}^{-3} \mathrm{Ce}(\mathrm{IV})$ was made by dissolving ceric sulfate tetrahydrate in $0.60 \mathrm{~mol} \mathrm{dm}^{-3}$ sulfuric acid. Also, a $1.0 \mathrm{~mol} \mathrm{dm}^{-3}$ solution of hydroxylamine hydrochloride was prepared in $3.0 \mathrm{~mol} \mathrm{dm}^{-3} \mathrm{HCl}$ for use as a reductant. A commercially available $1000 \mathrm{mg} \mathrm{dm}^{-3}$ standard of $\mathrm{Sb}$ (III) (Merck, Darmstadt, Germany) in $2.0 \mathrm{~mol} \mathrm{dm}^{-3} \mathrm{HCl}$ was used as a stock standard solution. A $1000 \mathrm{mg} \mathrm{dm}^{-3} \mathrm{Sb}(\mathrm{V})$ stock solution was prepared by dissolving potassium pyroantimonate in conc. $\mathrm{HCl}$. Working solutions of $\mathrm{Sb}(\mathrm{III})$ and $\mathrm{Sb}(\mathrm{V})$ were prepared daily by serial dilution of the standard stock solutions with 6.0 and $3.0 \mathrm{~mol} \mathrm{dm}^{-3}$ $\mathrm{HCl}$, respectively. Both standard solutions were also used for preparation of mixed sample solutions containing $\mathrm{Sb}(\mathrm{III})$ and $\mathrm{Sb}(\mathrm{V})$ in $6.0 \mathrm{~mol} \mathrm{dm}{ }^{-3} \mathrm{HCl}$. All glassware was soaked in $20 \%$ nitric acid and thoroughly cleaned before use.

\section{Apparatus}

For the FI-CL measurements, as illustrated in Fig. 1, a

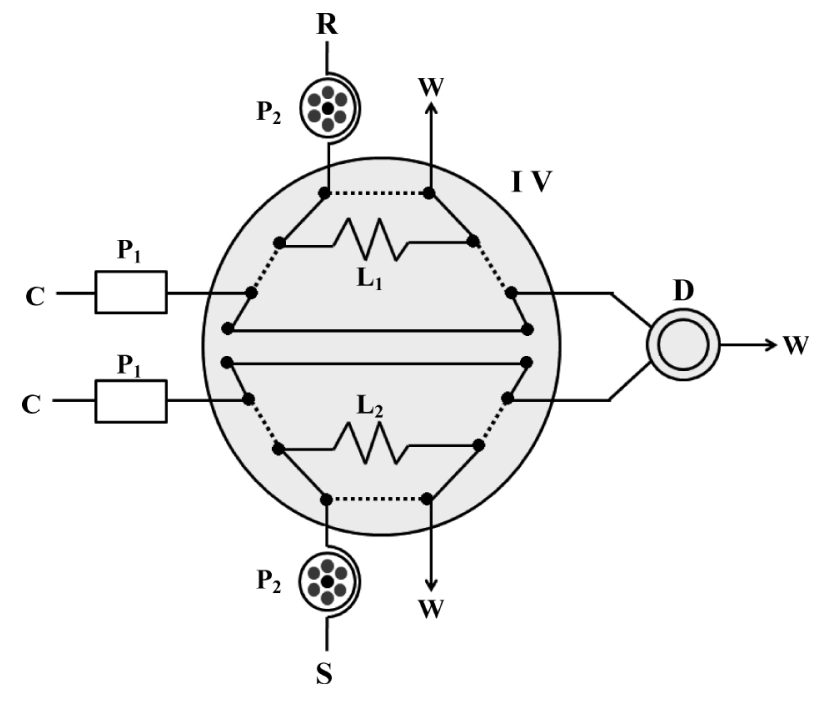

Fig. 1 Schematic flow diagram for the RMM-CL determination of antimony. C, carrier; $\mathrm{L}_{1}$, reagent loop $\left(100 \mathrm{~mm}^{3}\right) ; \mathrm{L}_{2}$, sample loop $\left(100 \mathrm{~mm}^{3}\right) ; \mathrm{P}_{1}$, plunger pump $\left(2.5 \mathrm{~cm}^{3} \mathrm{~min}^{-1}\right) ; \mathrm{P}_{2}$, peristaltic pump; $\mathrm{R}$, reversed micellar oxidant reagent; $S$, sample; $D$, detector; IV, injection valve in the load (-) and injection (‥) positions; W, waste.

multi-component instrument composed of a Hitachi (Tokyo) Model K-1000 FI analyzer equipped with a 16-port rotary programmed automatic injection valve, a Tosoh (Tokyo) Model CCPD computer-controlled pump unit, and a Niti-on (Funahashi) Model LF-800 photometer with spiral flow cell $\left(70 \mathrm{~mm}^{3}\right)$ was used as previously reported. ${ }^{29}$ PTFE tubing of $0.5 \mathrm{~mm}$ i.d. was used throughout the flow system. A Shimadzu (Kyoto) Model C-R6A computer-controlled recorder was used to record CL signals.

Absorption measurements were recorded with a Hitachi (Tokyo) Model U-3900 UV-visible spectrophotometer, equipped with $1 \mathrm{~cm}$ quartz cells thermostatted at $25.0 \pm 0.1^{\circ} \mathrm{C}$, unless otherwise indicated.

\section{Liquid-liquid extraction procedure}

In the extraction procedure for $\mathrm{Sb}(\mathrm{V})$, an aqueous sample

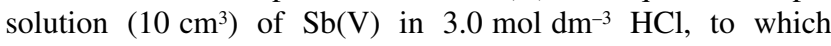

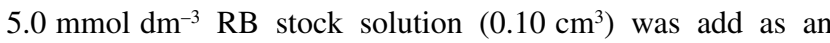
extraction reagent, was placed in a separating funnel and $10 \mathrm{~cm}^{3}$ of toluene as a solvent for extraction was added to it. The mixture was shaken for approximately $5 \mathrm{~min}$ and was allowed to stand ( $c a .5 \mathrm{~min}$ ) until the two phases were separated out. The upper organic layer was then subjected to CL analysis as mentioned below.

In the procedure for $\mathrm{Sb}(\mathrm{III}), \mathrm{Sb}(\mathrm{III})$ must first be converted to $\mathrm{Sb}(\mathrm{V})$ using an oxidizing agent. ${ }^{32}$ Cerium(IV) is one of the few suitable oxidizing agents and causes rapid oxidation at room temperature. As only a slight excess is needed, $0.50 \mathrm{~cm}^{3}$ of the $\mathrm{Ce}$ (IV) solution $\left(0.10 \mathrm{~mol} \mathrm{dm}{ }^{-3}\right)$ was added to $5.0 \mathrm{~cm}^{3}$ of the aqueous sample solution of $\mathrm{Sb}$ (III) in $6.0 \mathrm{~mol} \mathrm{dm}^{-3} \mathrm{HCl}$, then diluted to a final volume of $10 \mathrm{~cm}^{3}$ with water. After the oxidation of $\mathrm{Sb}$ (III), only a slight excess $\left(10 \mathrm{~mm}^{3}\right)$ of the hydroxylamine hydrochloride reductant $\left(1.0 \mathrm{~mol} \mathrm{dm}^{-3}\right)$ is added to the sample solution for reducing excess $\mathrm{Ce}(\mathrm{IV})$, which otherwise would oxidize $\mathrm{RB}$ and thus interfere with the extraction. For the resultant sample solution, the subsequent extraction procedure was conducted in the same manner as mentioned above for $\mathrm{Sb}(\mathrm{V})$. The same procedures for oxidation with $\mathrm{Ce}(\mathrm{IV})$, reduction of excess $\mathrm{Ce}(\mathrm{IV})$, addition of $\mathrm{RB}$ and 
Table 1 Optimum experimental and instrumental operating conditions

\begin{tabular}{|c|c|}
\hline \multicolumn{2}{|l|}{ Solvent extract system } \\
\hline $\mathrm{HCl}$ concentration & $3.0 \mathrm{~mol} \mathrm{dm}^{-3}$ \\
\hline Rhodamine B concentration & $50 \mu \mathrm{mol} \mathrm{dm}-3$ \\
\hline Aqueous/organic volume ratio & $1: 1$ \\
\hline Mixing and phase separation time & $5 \mathrm{~min}$, each \\
\hline Oxidizing agent $\mathrm{Ce}$ (IV) concentration & $5.0 \mathrm{mmol} \mathrm{dm}^{-3}$ \\
\hline $\begin{array}{l}\text { Reducing agent } \mathrm{NH}_{2} \mathrm{OH} \cdot \mathrm{HCl} \\
\text { concentration }\end{array}$ & $1.0 \mathrm{mmol} \mathrm{dm}^{-3}$ \\
\hline \multicolumn{2}{|l|}{ RMM-CL system } \\
\hline $\begin{array}{l}{[\mathrm{Ce}(\mathrm{IV})] \text { in the CTAC reversed }} \\
\text { micellar solution }\end{array}$ & $\begin{array}{l}1.0 \mathrm{mmol} \mathrm{dm}^{-3} \text {, calculated } \\
\text { on a final volume total } \\
\text { solution basis }\end{array}$ \\
\hline $\begin{array}{l}{\left[\mathrm{H}_{2} \mathrm{SO}_{4}\right] \text { in the } \mathrm{Ce}(\mathrm{IV}) \text { oxidant }} \\
\text { solution }\end{array}$ & $0.60 \mathrm{~mol} \mathrm{dm}^{-3}$ \\
\hline$R_{\mathrm{w}}\left(=\left[\mathrm{H}_{2} \mathrm{O}\right] /[\mathrm{CTAC}]\right)$ & 5.0 \\
\hline $\begin{array}{l}{[\mathrm{CTAC}] \text { in the reversed micellar bulk }} \\
\text { organic solvent }\end{array}$ & $0.11 \mathrm{~mol} \mathrm{dm}^{-3}$ \\
\hline Reversed micellar bulk solvent & $\begin{array}{l}\text { 1-Hexanol-cyclohexane } \\
\quad\left(X_{\mathrm{h}}=0.10\right)\end{array}$ \\
\hline \multicolumn{2}{|l|}{ Flow system } \\
\hline Sample and reagent loop size & $100 \mathrm{~mm}^{3}$, each \\
\hline Carrier & $\begin{array}{l}\text { 1-Hexanol-cyclohexane } \\
\quad\left(X_{\mathrm{h}}=0.10\right)\end{array}$ \\
\hline Flow rate & $2.5 \mathrm{~cm}^{3} \mathrm{~min}^{-1}$ \\
\hline
\end{tabular}

toluene extraction were also performed for the determination of total antimony, $\mathrm{Sb}(\mathrm{III})+\mathrm{Sb}(\mathrm{V})$, in the mixed sample solutions that contained variable concentrations of $\mathrm{Sb}$ (III) and a constant

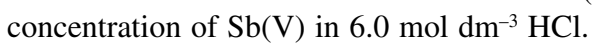

\section{CL measurement}

Certain volumes of the oxidant solution of $0.10 \mathrm{~mol} \mathrm{dm}^{-3}$ $\mathrm{Ce}(\mathrm{IV})$ were dispersed in a reversed micellar bulk solvent of 1-hexanol in cyclohexane (the mole fraction of 1-hexanol $X_{\mathrm{h}}=0.10$ ) containing $0.11 \mathrm{~mol} \mathrm{dm}^{-3}$ CTAC to prepare their reversed micellar solutions. The $\mathrm{Ce}(\mathrm{IV})$ concentration in the CTAC reversed micellar solution, calculated on a final volume

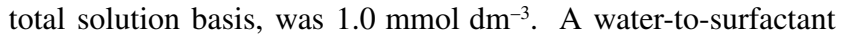
molar concentration ratio, $R_{\mathrm{w}}\left(=\left[\mathrm{H}_{2} \mathrm{O}\right] /[\mathrm{CTAC}]\right)$ of 5.0, was used in the present work. The FI system used was based on a merging-zone technique (Fig. 1). Peristaltic pumps were used to suck the ion-pair extracted solution and the reversed micellar oxidizing reagent solution of $\mathrm{Ce}(\mathrm{IV})$ into their respective $100 \mathrm{~mm}^{3}$ loops in the load position (straight line in Fig. 1), which were then inserted simultaneously into the respective carrier streams of 1-hexanol-cyclohexane $\left(X_{\mathrm{h}}=0.10\right)$ by switching the rotary injection valve to the injection position (dotted line in Fig. 1). Both the carrier streams were driven at the flow rate of $2.5 \mathrm{~cm}^{3} \mathrm{~min}^{-1}$. The reversed micellar solution of $\mathrm{Ce}(\mathrm{IV})$ was mixed with the ion-pair extracted solution in a $70-\mathrm{mm}^{3}$ spiral-flow cell mounted in front of a phototube of the photometer, and the resultant CL signal was recorded. An aqueous solution of $1.0 \mathrm{mg} \mathrm{dm}^{-3} \mathrm{Sb}(\mathrm{V})$ or $8.2 \mu \mathrm{mol} \mathrm{dm}{ }^{-3} \mathrm{Sb}(\mathrm{V})$ was used to optimize experimental and chemical parameters. The optimum experimental conditions used for the FI-CL detection in this work are given in Table 1.

\section{Results and Discussion}

Ion-pair extraction and RMM-CL system

Numerous analytical procedures based on the formation of ion pairs between protonated organic compounds and negatively charged metal complexes extractable into organic solvents have been reported. ${ }^{33,34}$ Also, the application of the ion-pair formation between protonated $\mathrm{RB}$ and $\left[\mathrm{SbCl}_{6}\right]^{-}$to liquid-liquid extraction had been established earlier, ${ }^{32}$ and was employed in this work. The RB is first protonated in an acidic medium and is then associated with a negatively charged counterion containing antimony $(\mathrm{V})$. Because ion pairs in slightly polar organic solvents are more stable than in aqueous solutions, the ion pairs are then quickly and efficiently extracted into a slightly polar solvent, e.g. benzene or toluene. As toluene is more suitable for extracting ion pairs in terms of safety and low-cost, toluene was selected as the extractant in this work. However, toluene is not suitable for the stability of the CTAC reverse micelles. When the extract containing the ion-pair $\left(\mathrm{RBH}^{+}\left[\mathrm{SbCl}_{6}\right]^{-}\right)$was mixed with the reversed micellar solution of $\mathrm{Ce}(\mathrm{IV})$, the RMM-CL emission resulting from the oxidation reaction of $\mathrm{RB}$ was observed. In this work, we demonstrated that the compatibility of the extractant and reversed micellar bulk solvent is not necessarily important for obtaining sharp and reproducible CL signals. The CL intensity obtained from the oxidation of RB with $\mathrm{Ce}(\mathrm{IV})$ in the reverse micelles, as reported previously, ${ }^{28,29}$ is proportional to the amount of RB extracted one-on-one with antimony $(\mathrm{V})$, and thus the present procedure permits the indirect quantitative determination of antimony $(\mathrm{V})$.

\section{Optimization studies}

A series of experiments were performed to establish the optimum analytical conditions as to those given in Table 1. Especially, the extractability of the ion-pair depends on the $\mathrm{HCl}$ concentration in aqueous sample solutions and the CL emission is affected by the molar ratio, $R_{\mathrm{w}}\left(=\left[\mathrm{H}_{2} \mathrm{O}\right] /[\mathrm{CTAC}]\right)$, in the reversed micellar system; these are described below in detail. In our previous paper, ${ }^{29}$ it was noted that when the mole fraction of 1-hexanol in the reversed micellar bulk solvent used was 0.045 , the problem of turbidity was caused in the $R_{\mathrm{w}}$ range from beyond 5 up to over $c a$. 10. In the present procedure, a higher mole fraction of 1-hexanol $\left(X_{\mathrm{h}}=0.10\right)$ was used to overcome this problem, and transparent and homogenous solution of the CTAC reverse micelles was made without suppressing the CL emission. The other experimental parameters related to RMM-CL detection were close to those reported earlier. ${ }^{29}$

\section{Effect of the HCl concentration}

The formation of the $\left[\mathrm{SbCl}_{6}\right]^{-}$, as well as the protonation of the $\mathrm{RB}$ and, consequently, ion pair formation depend on the $\mathrm{HCl}$ concentration in aqueous sample solutions. The absorbance at the maximum wavelength $(564 \mathrm{~nm})$ of $\mathrm{RBH}^{+}\left[\mathrm{SbCl}_{6}\right]^{-}$in toluene, obtained by the above extraction procedure, was recorded as being a function of the $\mathrm{HCl}$ concentration in the aqueous sample solution, and is shown in Fig. 2. With an increase in the concentration of $\mathrm{HCl}$, an increase in the absorbance was observed, reaching a maximum around $3.0 \mathrm{~mol} \mathrm{dm}{ }^{-3}$, beyond which the absorbance declined.

The amounts of generated $\mathrm{RBH}^{2+}\left(\left[\mathrm{SbCl}_{6}\right]^{-}\right)_{2}$ and $\mathrm{RBH}^{2+} \mathrm{Cl}^{-}$ $\left[\mathrm{SbCl}_{6}\right]^{-}$increase in stronger concentrations of $\mathrm{HCl}$, but they do not compensate for the decreased extraction of $\mathrm{RBH}^{+}\left[\mathrm{SbCl}_{6}\right]^{-}$. Consequently, the total fraction of antimony extracted decreases with increasing acidity. An acid concentration of $3.0 \mathrm{~mol} \mathrm{dm}^{-3}$ $\mathrm{HCl}$ was selected as an optimum value.

\section{Effect of the $\left[\mathrm{H}_{2} \mathrm{O}\right] /[\mathrm{CTAC}]$ molar ratio}

The molar ratio, $R_{\mathrm{w}}$, significantly affects the physiochemical properties of the reverse micelles. By varying $R_{\mathrm{w}}$, one can modify the size of the reversed micellar water pool. ${ }^{17,18,35}$ The 


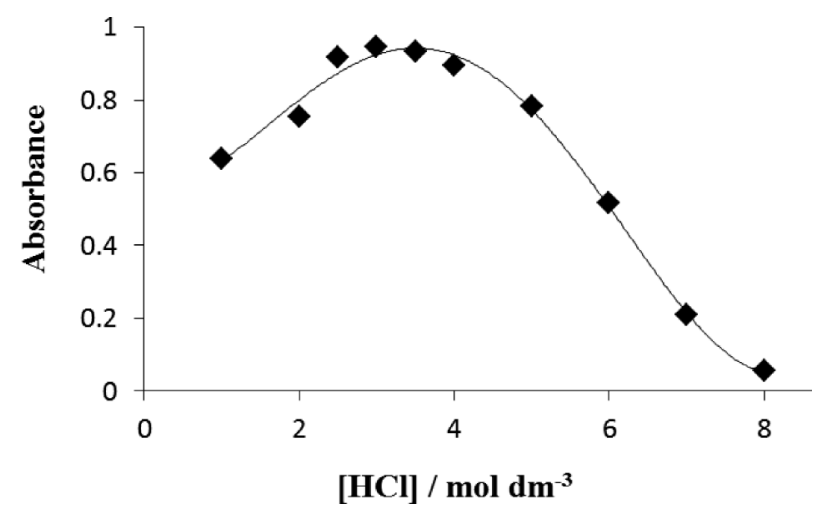

Fig. 2 Effect of $\mathrm{HCl}$ concentration in aqueous sample solutions on the absorbance of the RB species in the extract. Experimental conditions are given in Table 1.

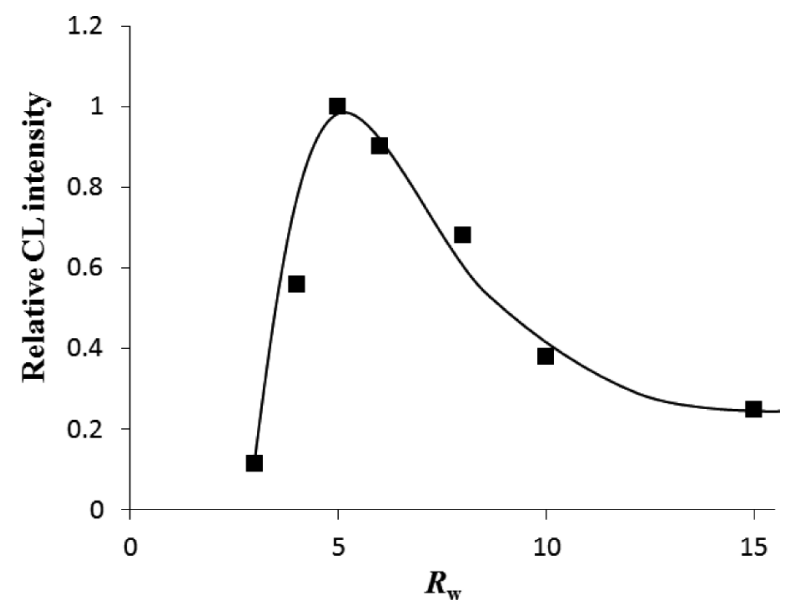

Fig. 3 Variation of CL intensity with the molar concentration ratio of water to surfactant, $R_{\mathrm{w}}$, in the reversed micellar solution of $0.11 \mathrm{~mol} \mathrm{dm}^{-3}$ CTAC in 1-hexanol-cyclohexane $\left(X_{\mathrm{h}}=0.10\right)$. Experimental conditions are given in Table 1.

$R_{\mathrm{w}}$ value was varied by changing the water concentration at a fixed amount of CTAC surfactant $\left([C T A C]=0.11 \mathrm{~mol} \mathrm{dm}^{-3}\right)$ in the reverse micellar solution. As shown in Fig. 3, the CL signal increased with an increase in the $R_{\mathrm{w}}$ value. A maximum CL intensity was attained around $R_{\mathrm{w}}$ value of 5.0, which was chosen as an optimum $R_{\mathrm{w}}$ value. Similar behavior in the variation of the RMM-CL intensity with $R_{\mathrm{w}}$ was observed in our previous work. ${ }^{29}$ Increasing the $R_{\mathrm{w}}$ value caused an increase in the size of the reversed micellar water pools. It can be supposed that due to a decrease in the $\mathrm{Cl}^{-}$concentration in the water pools with an increase in volumes, the suppressing effect of the $\mathrm{Cl}^{-}$ion on the $\mathrm{Ce}(\mathrm{IV})$ activity in the pools is weakened and thus RB-Ce(IV) $\mathrm{CL}$ emission is enhanced. Meanwhile, after reaching the optimum $R_{\mathrm{w}}$, the ability of the reversed micellar microenvironment for the CL enhancement is lowered in larger pools, where the properties of water may be similar to those of the usual bulk water. ${ }^{17,18,35}$

\section{Analytical performance}

An analytical CL signal was taken as the difference in the observed peak heights for the analyte and the blank. However, the blank signal was negligibly small. Thus, the detection limit (DL) was given as the analyte concentration for which the
Table 2 Metals tested for possible interfering behavior in liquid-liquid extraction and CL determination of $\mathrm{Sb}(\mathrm{V})$

\begin{tabular}{|c|c|c|c|c|c|}
\hline \multirow{2}{*}{ Metal } & \multicolumn{2}{|c|}{$\begin{array}{l}\text { Relative CL } \\
\text { intensity }\end{array}$} & \multirow{2}{*}{ Metal } & \multicolumn{2}{|c|}{$\begin{array}{l}\text { Relative CL } \\
\text { intensitya }\end{array}$} \\
\hline & $10^{\mathrm{b}}$ & $100^{\mathrm{b}}$ & & $10^{\mathrm{b}}$ & $100^{\mathrm{b}}$ \\
\hline $\mathrm{Sb}(\mathrm{III})$ & 101 & 103 & $\mathrm{Cu}(\mathrm{II})$ & 102 & 100 \\
\hline $\mathrm{Au}(\mathrm{III})$ & 960 & - & $\mathrm{Pb}(\mathrm{II})$ & 110 & 102 \\
\hline $\mathrm{Fe}(\mathrm{III})$ & 93 & 100 & $\operatorname{Sn}(\mathrm{II})$ & 98 & 98 \\
\hline $\mathrm{Ga}$ (III) & 101 & 106 & $\mathrm{Hg}(\mathrm{II})$ & 101 & 101 \\
\hline Al(III) & 98 & 99 & $\mathrm{Zn}(\mathrm{II})$ & 97 & 100 \\
\hline $\mathrm{As}(\mathrm{III})$ & 105 & 97 & $\mathrm{Ni}(\mathrm{II})$ & 95 & 95 \\
\hline $\mathrm{Cr}(\mathrm{III})$ & 97 & 99 & $\mathrm{Co}(\mathrm{II})$ & 98 & 101 \\
\hline Bi(III) & 109 & 104 & $\operatorname{Ag}(\mathrm{I})$ & 104 & 96 \\
\hline
\end{tabular}

a. All CL intensities are relative to the CL signal (=100) for $8.2 \mu \mathrm{mol} \mathrm{dm}^{-3} \mathrm{Sb}(\mathrm{V})$ alone.

b. Metal-to- $\mathrm{Sb}(\mathrm{V})$ weight ratio.

analytical signal was three times higher than the noise level of the base line. Under optimized instrumental and chemical conditions, DLs of $0.25 \mu \mathrm{mol} \mathrm{dm}{ }^{-3} \mathrm{Sb}$ (III) and $0.20 \mu \mathrm{mol} \mathrm{\textrm {dm } ^ { - 3 }}$ $\mathrm{Sb}(\mathrm{V})$ were achieved. The DL values are superior to those attained $\left(29 \mu \mathrm{mol} \mathrm{dm}^{-3} \mathrm{Sb}(\mathrm{V})\right)$ by a flow method using absorptiometric detection following ion-pair extraction. ${ }^{36}$ The linear calibration graphs for $\mathrm{Sb}(\mathrm{III})$ and $\mathrm{Sb}(\mathrm{V})$ were obtained

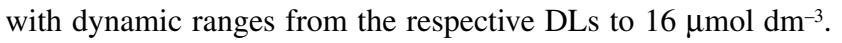
The relative standard deviations $(n=6)$ obtained at the $\mathrm{Sb}(\mathrm{III})$ concentration of $4.1 \mu \mathrm{mol} \mathrm{dm}{ }^{-3}$ and the $\mathrm{Sb}(\mathrm{V})$ concentration of $8.2 \mu \mathrm{mol} \mathrm{dm}^{-3}$ were $2.2 \%$ and $1.1 \%$, respectively.

\section{Interference effects}

The effect of some common metals, e.g. $\mathrm{Au}(\mathrm{III})$ and $\mathrm{Ga}(\mathrm{III}),{ }^{37,38}$ which can be given red or violet compounds of the type $\mathrm{RBH}^{+}\left[\mathrm{M}^{\mathrm{III}} \mathrm{Cl}_{4}\right]^{-}$, and other metal ions were examined to check possible interference. For the interference studies, $8.2 \mu \mathrm{mol} \mathrm{dm}^{-3}$ $\mathrm{Sb}(\mathrm{V})$ solutions containing the individual interfering species were used. The results obtained are summarized in Table 2. None of the species tested, except for $\mathrm{Au}(\mathrm{III})$, interfered with the $\mathrm{CL}$ determination of $\mathrm{Sb}(\mathrm{V})$ when present at an interferent-to- $\mathrm{Sb}(\mathrm{V})$ weight ratio of 10 and 100 . Because an ion-pair of $\mathrm{RBH}^{+}\left[\mathrm{AuCl}_{4}\right]^{-}$in $\mathrm{HCl}$ solution $\left(3.0 \mathrm{~mol} \mathrm{dm}^{-3}\right)$ can be considerable readily extracted into toluene, the presence of $\mathrm{Au}(\mathrm{III})$ caused an enhancement in the CL emission.

\section{Differential determination of antimony(III)/antimony $(V)$}

In the present extraction-CL detection system for mixed sample solutions containing $\mathrm{Sb}(\mathrm{III})$ and $\mathrm{Sb}(\mathrm{V})$, the crucial process of oxidizing $\mathrm{Sb}$ (III) with $\mathrm{Ce}(\mathrm{IV})$ was added prior to the extraction. When the concentration of $\mathrm{Sb}(\mathrm{III})$ alone was changed while keeping the content of $\mathrm{Sb}(\mathrm{V})$ constant in the sample solutions, a linear calibration graph for the total antimony, $\mathrm{Sb}(\mathrm{III})+\mathrm{Sb}(\mathrm{V})$, measured as the peak height was obtained using the oxidant, while almost the same CL signals were produced without use of the oxidant, as shown in Fig. 4. This indicates that $\mathrm{Sb}(\mathrm{V})$ alone is transferred to the organic phase and thus the effect of $\mathrm{Sb}(\mathrm{III})$ on the CL signals is negligibly small. As such, $\mathrm{Sb}(\mathrm{III})$ determination is easily possible from the difference.

\section{Conclusions}

An ion-pair formation and liquid-liquid extraction method 


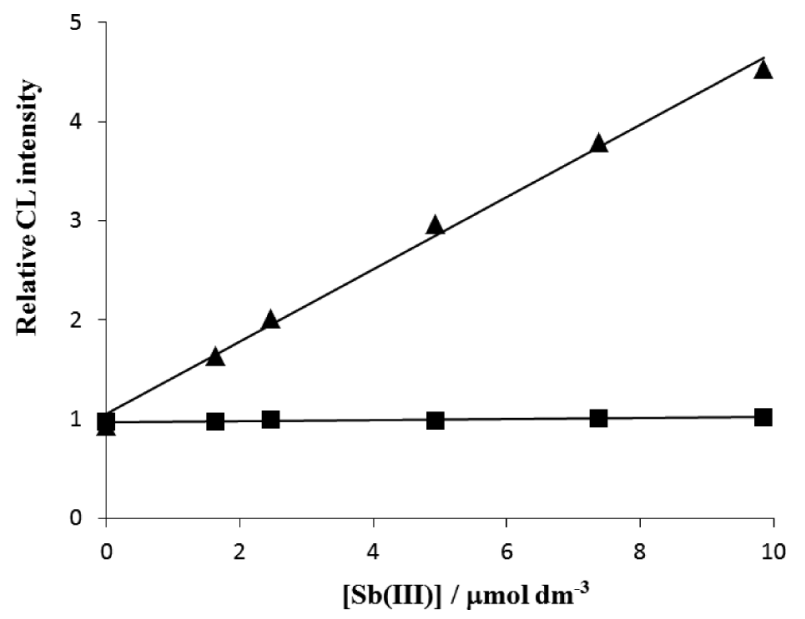

Fig. 4 Variation of the CL intensity with the concentration of $\mathrm{Sb}$ (III) in mixed sample solutions of $\mathrm{Sb}(\mathrm{III})$ and $\mathrm{Sb}(\mathrm{V})$ in the absence ( $\mathbf{\square})$ and presence ( $\Delta$ ) of $5.0 \mathrm{mmol} \mathrm{dm}^{-3} \mathrm{Ce}(\mathrm{IV})$.

coupled with CL detection based on the reversed micellar-mediated oxidation of RB with $\mathrm{Ce}(\mathrm{IV})$ was developed for the determination of $\mathrm{Sb}(\mathrm{V})$, where RB was used not only as an extracting reagent but also as a CL reagent. With a simple experimental setup using low-cost instrumentation, the proposed method is undoubtedly fast and sensitive. Modification of this technique provided for analyses of $\mathrm{Sb}(\mathrm{V})$ only, $\mathrm{Sb}(\mathrm{III})+\mathrm{Sb}(\mathrm{V})$, or $\mathrm{Sb}(\mathrm{III})$ and $\mathrm{Sb}(\mathrm{V})$ in the same sample using $\mathrm{Ce}(\mathrm{IV})$ oxidant cycling. However, before this method can be applied to samples of a biological and environmental nature, analytical efforts are certainly needed to identify potential interferents such as $\mathrm{Au}(\mathrm{III})$. Moreover, to provide automated, rapid and reproducible analyses of the aqueous samples of antimony using an on-line extraction-CL detection system, further studies are being undertaken to incorporate a membrane phase separator into the flow system.

\section{Acknowledgements}

This work was partially supported by a Grant-in-Aid for Scientific Research, No. 23550097, from the Ministry of Education, Science, Sports, and Culture, Japan. One of the authors, T. H. A. H., also thanks this Ministry for awarding a scholarship and Minia University, Egypt, for granting leave.

\section{References}

1. X. Jiang, S. Wen, and G. Xiang, J. Hazard. Mater., 2010, $175,146$.

2. A. López-Molinero, O. Mendoza, A. Callizo, P. Chamorro, and J. R. Castillo, Analyst, 2002, 127, 1386.

3. Y. C. Sun and J. Y. Yang, Anal. Chim. Acta, 1999, 395, 293.

4. J. Zheng, A. Iijima, and N. Furuta, J. Anal. At. Spectrom., 2001, 16, 812 .

5. N. V. Semenova, L. O. Leal, R. Forteza, and V. Cerdá, Anal. Chim. Acta, 2005, 530, 113.

6. A. Abbaspour and M. Najafi, Talanta, 2003, 60, 1079.

7. A. K. Campbell, in "Chemiluminescence Principles and Application in Biology and Medicine”, ed. E. Horwood,
Chap. 1, 1988, Chichester, UK.

8. M. J. Navas and A. M. Jimenez, Food Chem., 1996, 55, 7.

9. A. Fernandez-Gutierrez and M. de la. Pena, in "Molecular Luminescence Spectroscopy. Methods and Applications, Part 1", ed. S. G. Schulman, 1985, Wiley, New York, 463.

10. T. Fujiwara, K. Kurahashi, T. Kumamaru, and H. Sakai, Appl. Organomet. Chem., 1996, 10, 675.

11. D. A. Hinckly, P. G. Saybold, and D. P. Borris, Spectrochim. Acta, Part A, 1986, 42, 747.

12. K. Mandal, T. D. L. Pearson, and J. N. Demas, Anal. Chem., 1980, 52, 2184.

13. M. Y. Lü and S. P. Liu, J. Instrum. Anal., 2001, 20, 35.

14. J. G. Li, Y. R. Wang, Y. L. Tang, and Y. Q. Wei, Chin. J. Anal. Chem., 1997, 25, 590.

15. Y. Ma, X. Jin, M. Zhou, Z. Zhang, X. Teng, and H. Chen, Anal. Chim. Acta, 2003, 489, 173.

16. J. Georges, Spectrochim. Acta Rev., 1990, 13, 27.

17. M. P. Pileni, in "Structure and Reactivity in Reverse Micelles", ed. M. P. Pileni, 1989, Elsevier, Amsterdam, 44.

18. W. L. Hinze, in "Organized Assemblies in Chemical Analysis”, ed. W. L. Hinze, 1994, JAI Press, Greenwich, 37.

19. T. Fujiwara, N. Tanimoto, J.-J. Huang, and T. Kumamaru, Anal. Chem., 1989, 61, 2800.

20. T. Fujiwara, N. Tanimoto, K. Nakamura, and T. Kumamaru, Chem. Lett., 1991, 1137.

21. Imdadullah, T. Fujiwara, and T. Kumamaru, Anal. Chem., 1991, 63, 2348.

22. Imdadullah, T. Fujiwara, and T. Kumamaru, Anal. Chem., 1993, 65, 421.

23. Theingi-Kyaw, S. Kumooka, Y. Okamoto, T. Fujiwara, and T. Kumamaru, Anal. Sci., 1999, 15, 293.

24. T. Fujiwara, Theingi-Kyaw, Y. Okamoto, and T. Kumamaru, Anal. Sci., 1997, 13(suppl.), 59.

25. T. Fujiwara, I. U. Mohammadzai, H. Inoue, and T. Kumamaru, Analyst, 2000, 125, 759.

26. Theingi-Kyaw, T. Fujiwara, H. Inoue, Y. Okamoto, and T. Kumamaru, Anal. Sci., 1998, 14, 203.

27. T. Fujiwara, I. U. Mohammadzai, K. Kitayama, Y. Funazumi, and T. Kumamaru, J. Colloid Interface Sci., 2007, 310, 682.

28. T. H. A. Hasanin, S. Tsukahara, and T. Fujiwara, Anal. Sci., 2010, 26, 1247.

29. T. H. A. Hasanin, Y. Tsunemine, S. Tsukahara, Y. Okamoto, and T. Fujiwara, Anal. Sci., 2011, 27, 297.

30. T. A. Nieman, in "Chemiluminescence and Photochemical Reaction Detection in Chromatography”, ed. J. W. Birks, 1989, VCH, New York, 99.

31. T. Fujiwara and T. Kumamaru, Spectrochim. Acta Rev., 1990, 13, 399.

32. R. W. Ramette and E. B. Sandell, Anal. Chim. Acta, 1955, $13,455$.

33. M. Eisman, M. Gallego, and M. Valcarcel, Anal. Chem., 1992, 64, 1509.

34. A. M. Garcia, E. S. Uria, and L. Sanz-Medal, J. Anal. At. Spectrom., 1996, 11, 561.

35. J. Nishimoto, E. Iwamoto, T. Fujiwara, and T. Kumamaru, J. Chem. Soc. Faraday Trans., 1993, 89, 535.

36. L. A. Trivelin, J. J. R. Rohwedder, and S. Rath, Talanta, 2006, 68, 1536.

37. B. J. Macnulty and L. D. Woolland, Anal. Chim. Acta, 1955, 13, 154.

38. H. Onishi and E. B. Sandell, Anal. Chim. Acta, 1955, 13, 159. 